\title{
Earth Observation for Humanitarian Operations
}

\author{
Stefan Lang and Petra Füreder \\ Z_GIS, University of Salzburg, Austria·stefan.lang@sbg.ac.at
}

Full paper double blind review

\begin{abstract}
The protraction of crises, civil wars, and conflicts cause countless humanitarian disasters, on the level of individuals, families, and society as a whole. Technological innovation, including the optimisation of information flows in crisis situations, is a critical asset in the humanitarian domain, while the ultimate benchmark of the usefulness of any new 'gadget' will be its effectiveness on the ground, and the very fact of whether it saves lives in the long run. Humanitarian aid organizations do play a critical role in this respect; they are the ones to adopt, test, improve, and further develop any new technology, in close collaboration with those providing it. Over recent years, projects and initiatives have been brought up, where research institutions and humanitarian actors share both technological and practical experience in mutual exchange. Satellite Earth observation (EO) and Geographical Information Systems (GIS) were recently adopted by the humanitarian action community to cope with these challenges, and to close the information gap. The special session EO4Hum focuses on the potential of EO data and technologies to support humanitarian action in crisis and disaster response. Turning satellite data into relevant geospatial information products for humanitarian actors remains a great challenge therein.
\end{abstract}

\section{Introduction}

The protraction of crises, civil wars, and conflicts in the Middle East, East and Sub-Saharan Africa, as well as in many other regions of the world, still cause countless humanitarian disasters, on the level of individuals, families, and society as a whole. Currently, there are about 51.2 million people displaced, amongst them 33.3 million internally displaced people (IDPs), 16.7 million refugees, and 1.2 million asylum seekers (UNHCR 2014, NRC/IDMC 2014). Thereby, 'refugees', i.e. those who manage to cross international borders and are under the protection of the United Nations Refugee Agency (UNHCR), though ungraspable in numbers, remain the smaller share. The majority of people suffering forced migration are internally displaced - meaning they remain in their countries, seeking shelter in temporary settlements, mainly camps at any safer place. IDP camps are highly dynamic in nature, confronting humanitarian organizations with situations where fast decisions need to be made, while solid management structures are not yet in place. Reliable information is critical under these emergency conditions, but also later on when camps need to be managed and monitored. Due to their dynamic and unplannable nature, IDP camps may be considered the 'step child' of international humanitarian relief support. Thus, information regarding their existence and evolvement over time is particularly crucial (see chapter 2).

GI Forum - Journal for Geographic Information Science, 1-2015.

(C) Herbert Wichmann Verlag, VDE VERLAG GMBH, Berlin/Offenbach. ISBN 978-3-87907-558-4.

(C) ÖAW Verlag, Wien. ISSN 2308-1708, doi:10.1553/giscience2015s384. 
Technological innovation, including the optimisation of information flows in crisis situations, is a critical asset in the humanitarian domain, while - first and foremost - the people in need are the primary beneficiaries of any humanitarian action. The ultimate benchmark of the usefulness of any new 'gadget' will be its effectiveness on the ground, and the very fact whether it saves lives or not in the long run. Humanitarian aid organizations do play a critical role in this respect; they are the ones to adopt, test, improve and further develop any new technology, in close collaboration with those providing it. Over recent years, projects and initiatives have been brought up, where research institutions and humanitarian actors share both technological and practical experience in mutual exchange. Humanitarian aid, through mandates and missions, is entitled to ensure that humanitarian action is targeted to the right people at the right place at the right time. New tools and techniques may help, if used in the right way. Non-governmental organizations (NGOs) such as Médecins Sans Frontières (MSF), do rely on up-to-date (often 'real-time'), yet reliable (i.e. not misleading) information to plan, direct, and at times correct, their operations and respective logistics on the ground
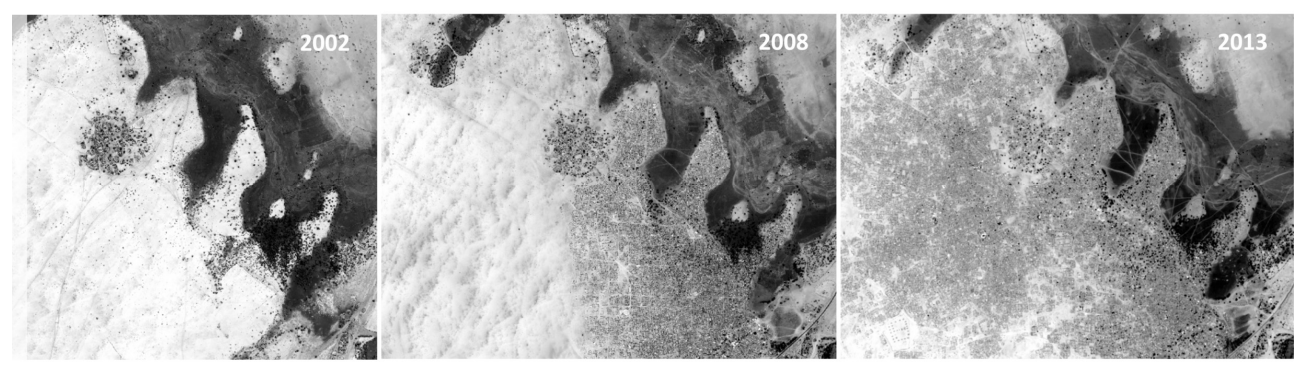

Fig. 1: Development of the IDP camp Zam Zam, Darfur, Sudan as observed on VHR imagery from 2002, 2008 and 2013 (from LANG et al. in press, modified)

\section{Earth Observation in Support to Humanitarian Action}

Depending on type and intensity of humanitarian disasters, the required mission-critical information most often cannot be gathered in a proper timeframe by local actors on the ground (LANG et al. 2010). Satellite Earth observation (EO) and Geographical Information Systems (GIS) were recently adopted by the humanitarian action community, to cope with these challenges and to close the information gap: we currently observe rapid proliferation of very high resolution (VHR) satellites, drones, globe browsers (Google Earth), online GIS, crowd mapping (OpenStreetMap, Ushahidi), mobile applications, and so forth - across all levels of intervention and irrespective of any particular geographic area.

Remote sensing, in particular in combination with advanced analysis techniques, has become a decision-supporting tool for humanitarian professionals. Due to its observational power, ubiquitous usage and availability (BJORGO 2001), remote sensing and derived information products are complementary data sources to field-based surveys enriching the pool of spatially aware technologies for humanitarian relief support (VERJEE 2011, COWAN 2011). Remote sensing as an objective imaging device captures data over large areas under equal conditions and taken from a constant orbital view. Thus, remote sensing entails a 
trend for a 'democratizing tool', designed to reveal the situation 'as is', non-distorted, nonmanipulated, and potentially accessible to everyone (LANG et al., in press).

Humanitarian response benefits from general assets of remotely sensed data that poses the following assets over conventional field mapping (ibid., see Table 1). (1) From a distance the core principle of remote sensing data, means collecting data without physical contact, which is critical to crisis-related applications. Often the area affected by the crisis is inaccessible, difficult to reach, or too dangerous to enter, rendering remote sensing the only information source available. (2) Depending on the spatial resolution of the satellite sensor, areas can be covered with variable extent, under the same imaging conditions and characteristics. The trade-off between resolution and extent is a limiting factor that is also reflected in costs and timeliness of data provision. (3) Satellite data, technically speaking, and leaving aside the actual availability often limited by weather conditions and competing orders, are globally available with a coverage rate of approximately $95 \%$ of the inhabitable space of the globe, and factually $100 \%$ of the permanent settlement area. (4) Time-series, i.e. repetitive acquisition and analysis of satellite data, not only enables constant monitoring in future time steps, but also ex-post assessments by past sequences. This is a key factor for estimating detected trend patterns in a more reliable matter.

Table 1: General assets in using remote sensing data and their potential as translated to humanitarian action

\begin{tabular}{lcl}
\hline Asset & \multicolumn{2}{c}{ Potential for humanitarian action } \\
\cline { 2 - 3 } & $\checkmark$ & No direct access required \\
\cline { 2 - 3 } & $\checkmark$ & Objective source of information \\
\hline 'Arom a distance' & $\checkmark$ & Cost-effective compared to field data collection \\
\hline 'Level of detail' & $\checkmark$ & Same conditions over large areas \\
& $\checkmark$ & Time-efficient data collection \\
\hline 'Global availability* & $\checkmark$ & Control of level-of-detail \\
\cline { 2 - 3 } & $\checkmark$ & Overview vs. detailed information \\
\hline 'Time series, monitor- & $\checkmark$ & Comparable data \\
ing' (including retro- & $\checkmark$ & Fast and easy access to data \\
spectively) & $\checkmark$ & Objective source of documentation how a situation looked \\
& & before a critical situation emerged \\
& $\checkmark$ & Validate other sources of information (e.g. from field data) \\
& $\checkmark$ & Ex-post evidence on past situations, events, changes
\end{tabular}



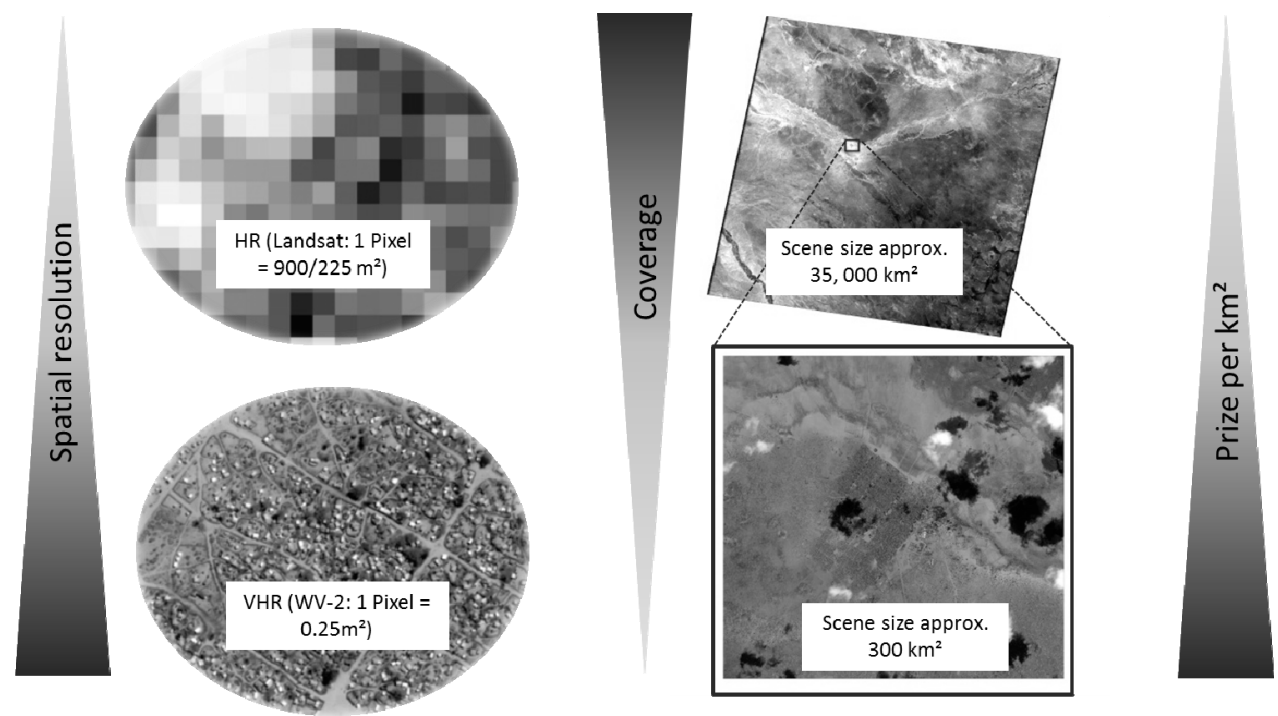

Level of detail and information captured by VHR imagery
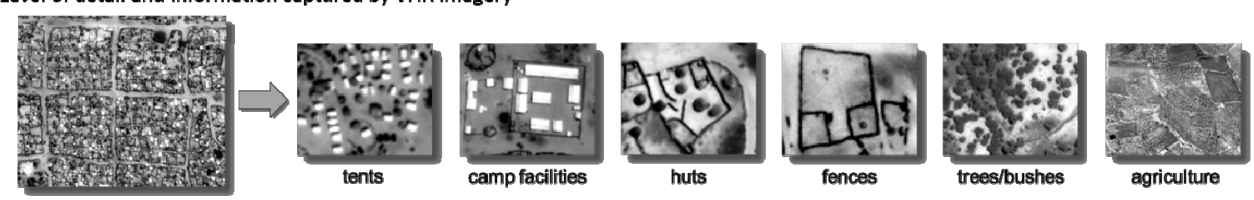

Fig. 2: The practical use of remote sensing data requires a demand-driven trade-off among technical assets and costs. Large coverage with high resolution is not feasible, both technically and cost-wise (from LANG et al. in press, modified)

\section{International Collaboration Framework}

Triggered by the advent and operational usage of VHR data that enabled the observation of people through 'direct indicators', e.g. dwellings (EHRLICH et al. 2009), more than a decade back, and boosted by the collaborative relief support of the geospatial community at large in the aftermath of the Haiti Earthquake 2010, we nowadays have a wide collaboration network in place with fruitful exchange between academic institutions and the community of practice. One example is the Humanitarian OpenStreetMap Team (HOT), formed to act as a bridge between the humanitarian responders and the OpenStreetMap community (LANG et al. in press).

Next to these non-governmental collaborative initiatives, there are institutional mechanisms in place on a European level and globally. The disaster risk reduction community is nowadays embedded in international crisis response mechanisms that rely on the usage of realtime EO satellite information and other geospatial information (International Charter on Space and Major Disasters, Copernicus Emergency Mapping Service, etc.). However, this mainly applies to natural and technical hazards. Humanitarian disasters caused by violent conflicts and regional crises are not directly addressed by these mechanisms. The United 
Nations are running an own unit, UNOSAT, which provides general information products under UN mandate. The REACH initiative (www.reach-initiative.org) is a joint initiative of international non-governmental organizations to facilitate the development of information tools and products to support evidence-based decisions in all phases of humanitarian action (ibid.).

There are ongoing discussions within the European Copernicus (formerly: GMES) programme on how to deal with EO-based information services for humanitarian action; no conclusive scenario is shaped. One reason being that NGOs are often concerned to threaten or even lose their independence when being involved in larger institutional mechanisms as the EU External Action Service (EEAS), that do not cover humanitarian action exclusively.

Such collaborative initiatives require a phase of mutual trust-building, joint developments of required information services, and setting up the required funding scheme. Technical innovation in the humanitarian domain relies on external funds, including from private sponsors. Over recent years, Z_GIS in close collaboration with MSF Austria has set up a role model for an operational service for humanitarian action. After a phase of mutual trustbuilding and collection of needs, a funding scheme through a private foundation was initiated. The 'population monitoring' service started to become operational in 2012, with constant improvements and adaptations since then. Two more information services are currently under development - the 'water exploration' and the 'environmental impact' (sub-) service. The service as such operates in a triangle relationship: The NGO (here: MSF), represents the user that receives, uses, and evaluates the products which are delivered (and developed further) within the information service. The service provider (here: Z_GIS) is equipped with the technical know-how and has access to critical data and tools in a non-forprofit environment. A private foundation, under specific conditions that the NGO complies with, finances these activities and enables a sustaining service scenario.

\section{Scope of the EO4Hum Workshop}

The special session EO4Hum focuses on the potential of EO data and technologies to support humanitarian action in crisis and disaster response. A large variety of different optical as well as radar sensor types can provide data at all kinds of spatial, temporal, and spectral resolution, applicable for many different humanitarian disaster scenarios. Turning this data into relevant geospatial information products for humanitarian actors is one challenge that will be addressed. To jointly discuss recent developments we welcome contributions from related research and practical application fields, including new methods, tools, and technologies for providing geospatial information products related to all phases of humanitarian crises (emergency, recovery and the development towards stable livelyhoods). The topics include: $a$. monitoring displaced population; $b$. early-warning indicators for humanitarian crisis; $c$. reference maps (including open and crowd sourced data); $d$. crisis monitoring (water supplies, infrastructure, natural resources); $e$. assessment of mid- to long-term effects of humanitarian crises; $f$. international initiatives as the ones mentioned above.

The selection of contributions in the following Section illustrates a broad range of application-oriented usages of EO and auxiliary data in the humanitarian domain: P. FÜREDER et al. discuss the potential of VHR satellite data for monitoring displaced people in crisis situations with a focus on supporting humanitarian operations during the conflict in 
South Sudan over a two year timespan. Y. REBoIs et al. discuss the use of satellite imagery and related sources by the International Committee of the Red Cross in the light of shifting foci and new possibilities in targeted humanitarian aid. The challenge of automated dwelling extraction in refugee camps with increasing tree coverage is addressed by F. LÜTHJE et al. Environmental impact of refugee/IDP camps is addressed by a series of papers: $O$. KRANZ et al. discuss the capacity of a multi-sensor, multi-scale assessment of the environmental impact of camps in the context of climatic variability. Similarly but more generally, M. HAGENLOCHER et al. present a multi-stage, rapid-to-detail EO-based approach for the assessment of the environmental impact. Looking at a different source of EO information, A. BRAUN and V. HochSCHILD combine SAR and optical data for investigating environmental parameters including change, and S. LANGER and D. TIEDE look at long-term monitoring of a camp's environmental impact based on Landsat time series, in particular the effect of de-forestation and re-forestation during the entire lifespan of the Lukole camp(s), Tanzania. With a focus on user validation of EO-based information products, S. D'OlEIRE-OLTMANS et al. introduce a validation strategy for client-specific map products of the European Copernicus security service. The team around S. de LABORDERIE et al. highlight the supportive power of satellite imagery in combating epidemics such as Ebola, and discuss experiences from MSF therein. Likewise utilizing the indicative power of remote sensing, L. WENDT et al. present remote sensing and GIS tools to support drinking water supply in refugee/IDP camps.

\section{Acknowledgements}

The EO4Hum Workshop was embedded in the GI-Forum symposium. We are grateful to all engaged in organization, selection, and reviewing of papers. Conducting this workshop was co-funded by the Austrian Research Promotion Agency (FFG) under the Austrian Space Application Programme (ASAP) within the project EO4HumEn (contract no: 840081).

\section{References}

BJORGO, E. (2001), Supporting humanitarian relief operations. In: BAKER, J. C., O'CONNELL, K. M. \& Williamson, R. A. (Eds.), Commercial observation satellites: at the leading edge of global transparency. ASPRS RAND, Santa Monica, CA., 403-427.

CowAN, N. M. (2011), A geospatial data management framework for humanitarian response. 8th International ISCRAM Conference Lisbon, Portugal, 1-5.

Ehrlich, D., Lang, S., Laneve, G., Mubareka, S., Schneiderbauer S. \& Tiede, D. (Eds.) (2009), Can Earth observation help to improve information on population? Indirect population estimations from EO derived geospatial data. Remote Sensing from Space Supporting International Peace and Security. B. JASANI, M. PeSARESI, S. SCHNEIDERBAUER \& G. ZEUG (Ed.). Springer, Berlin, 211-237.

Lang, S., FÜreder, P., Kranz, O., CArd, B., Roberts, S., \& PAPP, A. (in press), Humanitarian emergencies: causes, traits and impacts as observed by remote sensing. In: Thenkabail, P. (Ed.), Remote Sensing Handbook (Vol. III - Water Resources, Disasters, and Urban. Taylor and Francis, New York (pages pending)). 
LAng, S., Tiede, D., Hölbling, D., FÜreder, P. \& ZeIL, P. (2010), EO-based ex-post assessment of IDP camp evolution and population dynamics in Zam Zam, Darfur. International Journal of Remote Sensing, 31 (21), 5709-5731.

Norwegian Refugee Council/InTERnal Displacement Monitoring CEnTRe (NRC/ IDMC) (2014), Global Overview 2014: people internally displaced by conflict and violence, 14 May 2014. http://www.refworld.org/docid/5374747ab.html (27 January 2015).

UN High COMMISSIONER FOR REFUGEES (UNHCR) (2014), UNHCR Global Trends 2013: War's Human Cost, 20 June 2014. http://www.refworld.org/docid/53a3df694.html (1 February 2015).

VERJEE, F. (2011), GIS Tutorial for Humanitarian Assistance. ESRI Press, Redlands, CA. 